\title{
Atuação do fisioterapeuta em unidades de terapia intensiva no contexto da pandemia de COVID-19
}

\author{
Approach of the physiotherapist in intensive care units in the \\ context of the COVID-19 pandemic
}

Alguns tipos de coronavírus podem infectar seres humanos, causando disfunções respiratórias graves. O SARSCoV-2 é o causador da COVID-19, doença que foi identificada pela primeira vez em Wuhan, na província de Hubei, República Popular da China, em 1 de dezembro de 2019. Em 31 de dezembro do mesmo ano foi reportado oficialmente o primeiro caso no mundo. A doença se disseminou por vários países e, em 11 de março de 2020, a Organização Mundial da Saúde definiu o surto como pandemia [1]. Até a redação deste editorial havia mais de 2,4 milhões de casos confirmados em 213 países, com mais de 163 mil mortes registradas no mundo devido à COVID-19 [1]. No Brasil, o primeiro caso foi confirmado em 25 de fevereiro de 2020, com aumento progressivo de pessoas acometidas em vários estados do país. Atualmente temos mais de 40 mil casos confirmados e letalidade de 6,3\% [2].

As estatísticas mostram que 80\% dos indivíduos diagnosticados com COVID-19 não necessitam hospitalização. Dentre os $20 \%$ hospitalizados, somente $15 \%$ precisarão de acesso à terapia intensiva. Nesse contexto, diversas ações estão sendo tomadas por os órgãos reguladores de assistência à saúde de vários países a fim de mitigar a alta demanda de leitos, equipamentos e profissionais necessários ao combate à pandemia. Além disso, as entidades de classe e associações profissionais de todo o mundo têm publicado guidelines no sentido de orientar a abordagem de pacientes com COVID-19 [3-5]. No Brasil, a Associação Brasileira de Fisioterapia Cardiorrespiratória e Fisioterapia em Terapia Intensiva (ASSOBRAFIR) disponibiliza em seu site várias recomendações para atuação frente ao COVID-19 [3].

$\mathrm{Na}$ terapia intensiva, o fisioterapeuta brasileiro está na linha de frente dos cuidados respiratórios avançados, respaldado pelas melhores evidências científicas. No entanto, a infecção causada pelo SARS-CoV-2 nunca ocorreu antes, trazendo um novo desafio para todos os pesquisadores e profissionais de saúde. A COVID-19 surgiu há poucos meses e se disseminou rapidamente pelo mundo, não havendo tempo suficiente para o desenvolvimento de ensaios clínicos e muito menos revisões sistemáticas que possam direcionar as intervenções. As recomendações para o tratamento têm sido elaboradas com base na experiência de países que já enfrentaram ou enfrentam um grande número de casos de COVID-19, nas publicações sobre o tratamento de outras coronaviroses, como a Síndrome Respiratória do Oriente Médio (causada pelo coronavírus MERS-CoV) e a Síndrome Respiratória Aguda Grave (causada pelo coronavírus SARS-CoV), bem como nos estudos sobre a Síndrome do Desconforto Respiratório Agudo (SDRA) [4].

Devido ao elevado risco de contaminação, existem diferenças entre o ambiente de terapia intensiva geral e uma UTI para pacientes com COVID-19. Nesta, é imprescindível que os profissionais utilizem equipamento de proteção individual (EPI), incluindo capote, luvas, máscara com alta capacidade de filtração (N95 ou PFF2), touca e óculos ou 
protetor facial [1]. Esses equipamentos trazem desconforto para os profissionais e podem inclusive causar lesões cutâneas, como é o caso da máscara facial [1]. Além disso, o percentual de pacientes ventilados mecanicamente com insuficiência respiratória grave é extremamente elevado. Pacientes em ventilação espontânea podem subitamente evoluir para necessidade de intubação e instituição de ventilação mecânica, o que pode perdurar por até 2 a 3 semanas. Por esse motivo, senão todos, a grande maioria dos pacientes encontra-se sob oxigenoterapia ou ventilação mecânica invasiva, necessitando de atenção fisioterapêutica intensiva.

0 agravamento da doença é caracterizado por hipoxemia importante, resultante de diferentes processos fisiopatológicos que afetam a relação ventilação-perfusão [6]. Em geral, preconiza-se o uso de dispositivos de oxigenoterapia de baixo fluxo, tais como o cateter nasal e máscara sem reinalação com bolsa reservatório para minimizar a dispersão de aerossóis, visto que a doença é altamente contagiosa por meio de gotículas contendo o vírus [3]. A aplicação de oxigenoterapia nasal de alto fluxo ou ventilação não invasiva, mesmo sob condições de biossegurança consideradas “ideais", envolve diversos questionamentos quanto a sua relação risco-benefício. Durante a ventilação mecânica invasiva, para evitar a dispersão de aerossóis, deve-se utilizar sistema de aspiração fechado, filtro trocador de calor e umidade próximo à via aérea do paciente, além de filtro de barreira na extremidade distal do ramo expiratório do circuito ventilatório [3]. A estratégia de ventilação protetora é recomendada, consistindo na aplicação de volumes e pressões que não causem hiperdistensão alveolar, além de valores adequados de pressão positiva ao final da expiração (PEEP) [3-6]. 0 uso da "PEEP Table" da ARDSnet (combinações pré-determinadas de PEEP e fração inspirada de oxigênio - $\mathrm{FiO}_{2}$ ) é controverso para pacientes com COVID-19, pois muitos indivíduos apresentam hipoxemia grave com complacência do sistema respiratório pouco reduzida ou até normal, não sendo responsivos ao aumento da PEEP [6]. Ao contrário, a elevação desnecessária da PEEP pode sobrecarregar o ventrículo direito e aumentar a alteração perfusional. Dessa forma, a PEEP deve ser ajustada individualmente, preferencialmente por meio de protocolo decremental para sua titulação. Outro procedimento que tem sido bastante utilizado é a posição prona (posicionamento em decúbito ventral) dos pacientes com troca gasosa gravemente comprometida (relação $\mathrm{PaO}_{2} / \mathrm{FiO}_{2}<150$ ) [3-5]. Por envolver riscos e contraindicações, essa conduta deve ser realizada de forma criteriosa e por equipe treinada, sabendo-se que nem todos os pacientes serão responsivos a ela. Visto que a VM é um dos fatores de risco para fraqueza muscular adquirida na UTI e que esses pacientes permanecem em ventilação por um período de até 3 semanas, devemos dar atenção à mobilização precoce/exercícios terapêuticos nesse contexto [3]. 0 fisioterapeuta, enquanto membro da equipe multidisciplinar, atua também na ressuscitação cardiopulmonar, auxílio à intubação traqueal e transporte de pacientes em VM, procedimentos que possuem particularidades em pacientes com COVID-19 [3].

A atuação do fisioterapeuta intensivista no contexto da COVID-19 não se restringe aos exemplos citados aqui. Além disso, a abordagem terapêutica deve ser individualizada. As condutas a serem aplicadas requerem avaliação e reavaliações frequentes, o que exige muita atenção e trabalho dos profissionais envolvidos. 0 que fizermos ou deixarmos de fazer pode interferir no prognóstico. Em um único plantão de 12 horas, o fisioterapeuta pode ter que realizar inúmeros procedimentos na UTI ou Emergência COVID, tais como: auxílio a intubações, várias pronações e retornos à posição supina, muitas monitorizações, titulações de PEEP, ajustes da ventilação mecânica, recrutamentos alveolares, desmames, extubações, atuação em ressuscitações cardiopulmonares, dentre outros. Devido à gravidade respiratória dos pacientes e risco constante de contaminação dos profissionais, a rotina de trabalho nesse ambiente é muito mais desgastante física e emocionalmente do que o usual. Por outro lado, essa pandemia evidenciou a importância do fisioterapeuta na terapia intensiva, promovendo o reconhecimento da sociedade em geral e dos gestores em saúde.

\section{Fernando Guimarães (10*}

\footnotetext{
* Professor Associado do Departamento de Fisioterapia, Chefe da Seção de Pacientes Internos do Serviço de Fisioterapia do Hospital Universitário Clementino Fraga Filho, Universidade Federal do Rio de Janeiro (UFRJ), Rio de Janeiro, RJ, Brasil.
} 


\section{Referências}

1. World Health Organization [Internet]. Coronavirus disease (COVID-19) Pandemic. 2020 [cited 2020 April 23]. Disponível em: https://tinyurl.com/yx6vexyp

2. Ministério da Saúde. Painel Coronavírus. 2020 [cited 2020 April 23]. Disponível em: https://covid.saude.gov.br/

3. Associação Brasileira de Fisioterapia Cardiorrespiratória e Fisioterapia em Terapia Intensiva. COVID-19. 2020[cited 2020 April 23]. Disponível em: https://assobrafir.com.br/ covid-19/

4. Alhazzani W, Møller MH, Arabi YM, Loeb M, Gong MN, Fan E, et al. Surviving Sepsis Campaign: guidelines on the management of critically ill adults with Coronavirus Disease 2019 (COVID-19). Intensive Care Med. 2020:1-34. doi: 10.1007/s00134-020-06022-5 [Epub ahead of print]

5. Associação de Medicina Intensiva Brasileira. Informações úteis sobre o novo Coronavírus COVID-19 para Terapia Intensiva. 2020 [cited 2020 April 23]. Disponível em: https://tinyurl.com/y9svuyj7

6. Gattinoni L, Chiumello D, Caironi P, Busana M, Romitti F, Brazzi L, et al. COVID-19 pneumonia: different respiratory treatment for diferent phenotypes? Intens Care Med. 2020:1-6. doi: 10.1007/s00134-020-06033-2 [Epub ahead of print] 